\title{
Stigma associated with mental health problems among young people in India: a systematic review of magnitude, manifestations and recommendations
}

\author{
Shivani Mathur Gaiha ${ }^{1,2^{*}}$ (D), Tatiana Taylor Salisbury ${ }^{3}$, Mirja Koschorke $^{4}$, Usha Raman $^{5}$ and Mark Petticrew ${ }^{2}$
}

\begin{abstract}
Background: Globally, 20\% of young people experience mental disorders. In India, only 7.3\% of its 365 million youth report such problems. Although public stigma associated with mental health problems particularly affects help-seeking among young people, the extent of stigma among young people in India is unknown. Describing and characterizing public stigma among young people will inform targeted interventions to address such stigma in India, and globally. Thus, we examined the magnitude and manifestations of public stigma, and synthesised evidence of recommendations to reduce mental-health-related stigma among young people in India.
\end{abstract}

Method: A systematic review and meta-analysis of observational studies was conducted. Nine electronic databases were searched and 30 studies $(n=6767)$ met inclusion criteria.

Results: Most studies (66\%) focused on youth training to become health professionals. One-third of young people display poor knowledge of mental health problems and negative attitudes towards people with mental health problems and one in five had actual/intended stigmatizing behavior $\left(1^{2}>=95 \%\right)$. Young people are unable to recognize causes and symptoms of mental health problems and believe that recovery is unlikely. People with mental health problems are perceived as dangerous and irresponsible, likely due to misinformation and misunderstanding of mental health problems as being solely comprised of severe mental disorders (e.g. schizophrenia). However, psychiatric labels are not commonly used/understood.

Conclusion: Public education may use symptomatic vignettes (through relatable language and visuals) instead of psychiatric labels to improve young people's understanding of the range of mental health problems. Recommended strategies to reduce public stigma include awareness campaigns integrated with educational institutions and content relevant to culture and age-appropriate social roles.

Keywords: Stigma, Mental health, Systematic review, India, Youth

\footnotetext{
*Correspondence: gaiha@stanford.edu

${ }^{1}$ Indian Institute of Public Health- Hyderabad, Public Health Foundation of India, Hyderabad, India

${ }^{2}$ Department of Public Health, Environments and Society, Faculty of Public

Health and Policy, London School of Hygiene and Tropical Medicine, London, UK

Full list of author information is available at the end of the article
}

(c) The Author(s). 2020 Open Access This article is licensed under a Creative Commons Attribution 4.0 International License, which permits use, sharing, adaptation, distribution and reproduction in any medium or format, as long as you give appropriate credit to the original author(s) and the source, provide a link to the Creative Commons licence, and indicate if changes were made. The images or other third party material in this article are included in the article's Creative Commons licence, unless indicated otherwise in a credit line to the material. If material is not included in the article's Creative Commons licence and your intended use is not permitted by statutory regulation or exceeds the permitted use, you will need to obtain permission directly from the copyright holder. To view a copy of this licence, visit http://creativecommons.org/licenses/by/4.0/ The Creative Commons Public Domain Dedication waiver (http://creativecommons.org/publicdomain/zero/1.0/) applies to the data made available in this article, unless otherwise stated in a credit line to the data. 


\section{Background}

Young people, including adolescents and young adults aged 10-24 years [1] are at a critical period in the prevention and treatment of mental health disorders. Globally, an estimated one in five young people experience a mental disorder [2]. Among adults with a mental disorder, $75 \%$ report first experiencing a mental disorder during this period [3]. Although public stigma universally prevents people who experience mental health problems (i.e. symptoms that are not sufficient to warrant a diagnosis of a mental disorder) and those with mental disorders from seeking counselling and treatment, $[4,5]$ the extent and manifestations of such stigma varies across cultures $[6,7]$. Public stigma is defined as interrelated 'problems of knowledge (ignorance), problems of attitudes (prejudice), and problems of behaviour (discrimination)' [8]. In India too, public stigma is an important factor in the underreported prevalence of mental disorders, [9, 10] with only $7.3 \%$ of young people in India reporting a mental disorder and fewer accessing treatment [9].

Mental-health-related public stigma negatively impacts help-seeking by young people to a larger extent than among adults [11-15]. Young people with mental health problems are more likely to experience greater social distance from the public [16]. Additionally, compared to adults, young people do not seek help for mental health problems due to characteristic fears about lack of confidentiality, peer pressure, a desire to be self-reliant, [17] and lack of knowledge to recognize mental health problems [18] or lack of awareness about mental-healthrelated services [4]. Unsurprisingly, adolescents in a study found it more difficult to disclose their mental health problems compared to young adults [19].

The level of mental-health-related stigma among young people in India remains unknown. Stigma research in the United States, Greece, and Japan [20-22] identifies social distance and discriminatory beliefs related to mental health problems and a systematic review found stigma of mental disorders associated with violence, unpredictability and disability in Latin America and the Caribbean [23]. With the largest young population in the world at 365 million, [24] and a large burden of untreated mental health problems, young people in India will likely face challenges in achieving their social and economic potential. In 2015-16, India's national mental health survey highlighted that data on such mental-health-related stigma were limited [9]. Reducing public stigma is an aim in India's national mental health policy, [25] and in April 2017, India passed a law protecting the right to equality and non-discrimination of people with mental illness [26]. Through a systematic review and meta-analysis, this study aims to estimate the magnitude or prevalence of mental-health-related public stigma among a sub-group of the Indian population, i.e. young people aged 10-24 years old belonging to the general population; identify common problems in knowledge, attitude and behaviours associated with mental health; and collate recommendations for reducing mental-health-related public stigma.

\section{Method}

\section{Eligibility criteria}

Studies were included in this systematic review if they assessed public stigma associated with mental health problems among young people (aged 10-24 years) in India. Quantitative and qualitative studies were included if they examined any component of mental-healthrelated public stigma: knowledge of mental health; attitude towards people with mental health problems; and (intended or actual) behaviour towards people with mental health problems. Studies were excluded if they focused on stigma experienced by people with a diagnosed mental disorder and caregivers, or vulnerable groups at rehabilitation centres, schools for special needs, prisons or shelters, exposed to violence or in conflict zones. These studies were excluded as they involved specific groups for whom explanatory models, quality of life, anticipated or experienced stigma related to personal/lived experiences and previously accessing care or treatment from mental health providers, likely influence knowledge about mental health problems, and attitude and behaviour towards people with mental health problems. Theoretical or methodological studies and protocols for systematic reviews, media articles and social media, policy statements, book reviews, interviews, and lists of books were excluded. No restriction was placed on language of publication or publication date.

\section{Information sources}

Nine databases were searched (PubMed, ADOLEC, CINAHL+, PsycINFO, Scopus, Social policy and practise, Global Health, Web of Science and IndMED). The search was started in October 2014, and the last search in all databases was conducted in September 2018. Results were managed in EndNote X9 [27].

Methods and findings are reported according to the Preferred Reporting Items for Systematic reviews and Meta-analyses (PRISMA) guidelines, see Supplementary material [28]. The search strategy is presented in Table 1.

\section{Study selection}

The first author conducted this search across all databases and reviewed all studies based on the eligibility criteria, by reading all titles; next, by reading selected abstracts; and lastly, by reading the full text and references. Wherever there was incomplete information to 
Table 1 Search strategy for studies of youth mental-health-related stigma in India

\begin{tabular}{|c|c|}
\hline Category & Search terms \\
\hline Stigma & 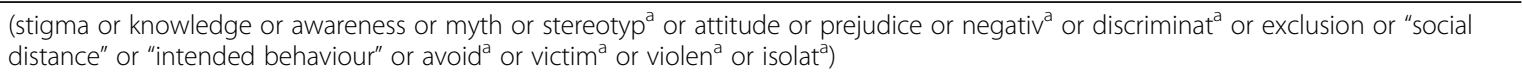 \\
\hline \multicolumn{2}{|l|}{ AND } \\
\hline $\begin{array}{l}\text { Mental } \\
\text { health }\end{array}$ & 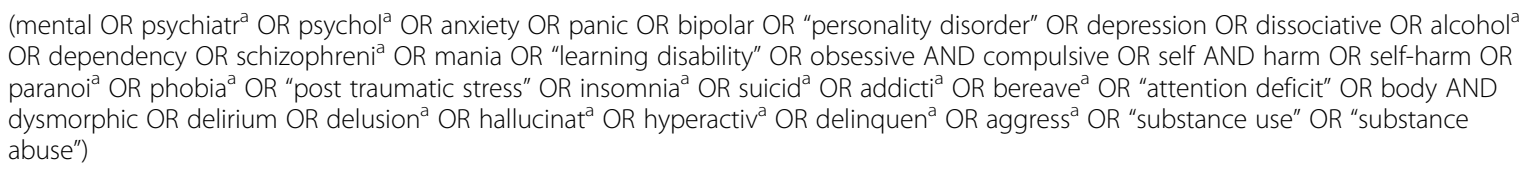 \\
\hline \multicolumn{2}{|l|}{ AND } \\
\hline India & (India) \\
\hline
\end{tabular}

asymbol of truncation in order to search keywords with varying endings and plural forms

include a study, it was moved to the next stage. If two or more articles on the same target population were found, the sample sizes and method were compared to confirm that the population studies were the same, and the most relevant article pertaining to eligibility criteria mentioned above, was retained for analysis. In the event that it was unclear if an article met review inclusion criteria, the first author discussed the article with the senior author.

\section{Data extraction}

The framework for data extraction included the following study characteristics: year of publication, sample size, location, \% females, participant age, independent variables, dependent/ outcome variables corresponding to knowledge, attitude and actual/ intended behaviour components of mental-health-related public stigma reported. We extracted data from all studies where authors self-identified that they measured knowledge, attitude and actual/ intended behaviour (components of public stigma). In addition, we reviewed abstracts followed by full-texts of studies found using our search strategy, and based on research question, individual measures and results corresponding to each public stigma component, data were extracted. Ultimately, a variety of measures were used to assess each of these stigma components. The risk of bias in included studies was assessed using the National Institutes of Health Quality Assessment Tool for Observational Cohort and Cross-Sectional Studies [29]. Qualitative narratives about knowledge, attitude and behaviour related gaps in public stigma and recommendations to reduce public stigma were collated from both qualitative and quantitative studies.

\section{Summary measures}

The principal measures used in the primary studies include percentages, means (standard deviation), differences between means, and levels of significance ( $p$ values).

\section{Synthesis and reporting}

First, demographic information of participants was extracted from all survey studies as per review objectives. Second, heterogeneity across studies assessed through $\mathrm{I}^{2}$ values determined if a meta-analysis of public stigma levels was appropriate. Similar to studies on prevalence of mental-health-related public stigma from Greece [21] and the United States, [20] we calculated such prevalence among youth. Public stigma levels were plotted by pooling study-wise percentage data on agreement with key statements related to knowledge, attitude and behaviour. If Standard Error (SE) was not reported by a study, the following formula was used: $\mathrm{SE}=\sqrt{\mathrm{p}(1-\mathrm{p})} / \mathrm{n}$ and $95 \% \mathrm{CI}=\mathrm{p} \pm 1.96 \mathrm{X}$ SE; where, $p=$ percentage of participants agreeing with items/ statements displaying poor knowledge, negative attitudes and stigmatising actual or intended behaviours and $\mathrm{CI}=$ Confidence Interval. If a study reported multiple items corresponding to each public stigma component, then the item with the lowest (stigmatizing) percentage was included. For example, within the attitude domain of public stigma, if a study reported different percentages of participants who believed that persons with mental illness 'lack will power,' 'are to blame' and 'can't handle responsibilities,' then the lowest percentage was plotted. Review Manager software (Version 5.3.5) was used to conduct the meta-analysis [30]. Random-effects models were generated to calculate the pooled percentage of public stigma as studies were likely from different regions of India, with variations in population, subject selection methods and measures.

Third, a narrative synthesis [adapted from existing Economic and Social Research Council (ESRC) guidance] [31] as per study objectives was used to collate and group qualitative findings corresponding to common conceptual gaps and perceptions related to each public stigma component (knowledge, attitude or behaviour) and recommendations to reduce stigma. Gaps were presented in descending order of frequency (number of times a theme was repeated across multiple studies) and 
importance (theme was included in the study discussion).

\section{Results}

Thirty studies were selected from 8872 articles in this review (Fig. 1). After removing 1040 duplicate articles, 7832 titles were screened based on the inclusion criteria. Next 291 abstracts were reviewed, of which 83 full-text studies were identified. One full-text article was unavailable [32].

\section{Study characteristics}

Twenty-eight quantitative studies [33-60] and two qualitative research studies $[61,62]$ were included in this review. A summary of data from these studies on sample size, age, gender, location (rural or urban), and outcomes related to public stigma domains: knowledge (K), attitude (A) and actual/ intended behaviour (B) is presented in Table 2.

Data from 6767 young people were included. Few studies included young people below 18 years of age [40, 44, $49,54,56,59,62,63]$ and studies varied by the proportion of females (33-100\%). Twenty studies assessed stigma among college students who were health professionals-in training, i.e. those studying medical, psychiatry, dental, pharmacy and nursing $[34,36-39,41-43,45,46,48,50-$ 54, 57, 60, 61]. Three studies included college students pursuing other disciplines [35, 58, 60]. Four secondary school-based studies were found $[44,55,56,59]$.

\section{Outcomes measured}

One-third of all studies assessing mental-health-related stigma among youth reported on attitude [35, 37, 38, $45-48,50,52,61]$. Eight studies assessed knowledge related to mental illness, [33, 39, 40, 53, 56, 58, 59, 62] seven studies assessed knowledge and attitude towards people with mental illness [41-43, 49, 54, 55, 60] and two studies focused on attitude and intended behaviour towards people with mental illness $[36,51]$. Only three studies assessed stigma comprehensively, across all components: knowledge, attitude and intended/actual behaviour $[34,44,57]$. As presented in the summary of study characteristics in Table 2, 16 out of 30 studies focused on stigma associated with mental illness (broadly defined, with no specific disorders included or excluded). The remaining studies were divided among epilepsy, phobia, suicide, and substance use (as specific disorders). Some of these studies included surveys with specific items/ scales measuring anxiety, panic disorder, bipolar disorder, depression, schizophrenia, and stress which are specific disorders/conditions. Stigma-related outcomes were measured using the Guttman social distance scale, $[34,51]$ Attitude To Psychiatry-29 [42, 45] and 30, [38] SUIATT questionnaire, [41] Opinions about Mental
Illness, [42, 60] Beliefs towards Mental Illness scale, [45] and the Attitude Scale for Mental Illness (ASMI) [34, 51]. Other studies reported developing their own survey questionnaires. No study used a vignette-based survey to assess recognition of signs and symptoms of mental illness.

\section{Risk of bias within studies}

Among quantitative studies, six studies were of good quality, and 11 each were of fair quality and poor quality (Table 3). One-third of all quantitative studies $(n=28)$, reported how the study population was selected: seven studies used purposive sampling, [33, 36-40, 48] and one study each used stratified random sampling, [34] two-stage random sampling, [53] and simple random sampling [59]. The rationale and calculation for sample size were presented in only one study [40]. The rate of participation was more than $50 \%$ in nine studies $[37,38$, 40-42, 49-52] and other studies did not report participation rates. Only 15 studies (53\%) used varied validated instruments to measure stigma [34, 36-38, 41, 42, 45, $46,50-52,54,60]$. Five studies adjusted mental health stigma outcomes with potential confounding variables $[33,34,51,52,58]$.

\section{Synthesis of results \\ Meta-analysis of the prevalence of youth mental health stigma}

Percentage outcomes related to knowledge, attitude and actual/intended behaviour were pooled, as the studies were all among youth and reported similar study designs. Approximately $33 \%$ of youth participants in 16 pooled studies had poor knowledge (95\% CI 25.8839.71; $p<0.001), 36 \%$ in 12 pooled studies had negative attitudes (95\% CI 28.74-44.18; $p<0.001$ ) and $22 \%$ had stigmatising, actual or intended behaviours in four studies $(95 \%$ CI 16.45-27.46; $p<0.001)$. However, this metaanalysis showed a high degree of heterogeneity, as the $\mathrm{I}^{2}$ value ranges from 95 to $99 \%$ (Fig. 2).

\section{Gaps in conceptualising mental illness}

In order of frequency and importance across 21 included studies, Table 4 presents a summary of gaps corresponding to each stigma component: knowledge, attitude and behaviour.

\section{Knowledge}

A significant majority of participants in some studies believed that people with a mental disorder can never recover $[36,37,45]$. One study suggests that in the Indian context, social distance was determined to a greater degree by lack of knowledge about recovery rather than perceived unpredictability or dangerousness [36]. Unsurprisingly, youth perceived that a battery of allopathic, 


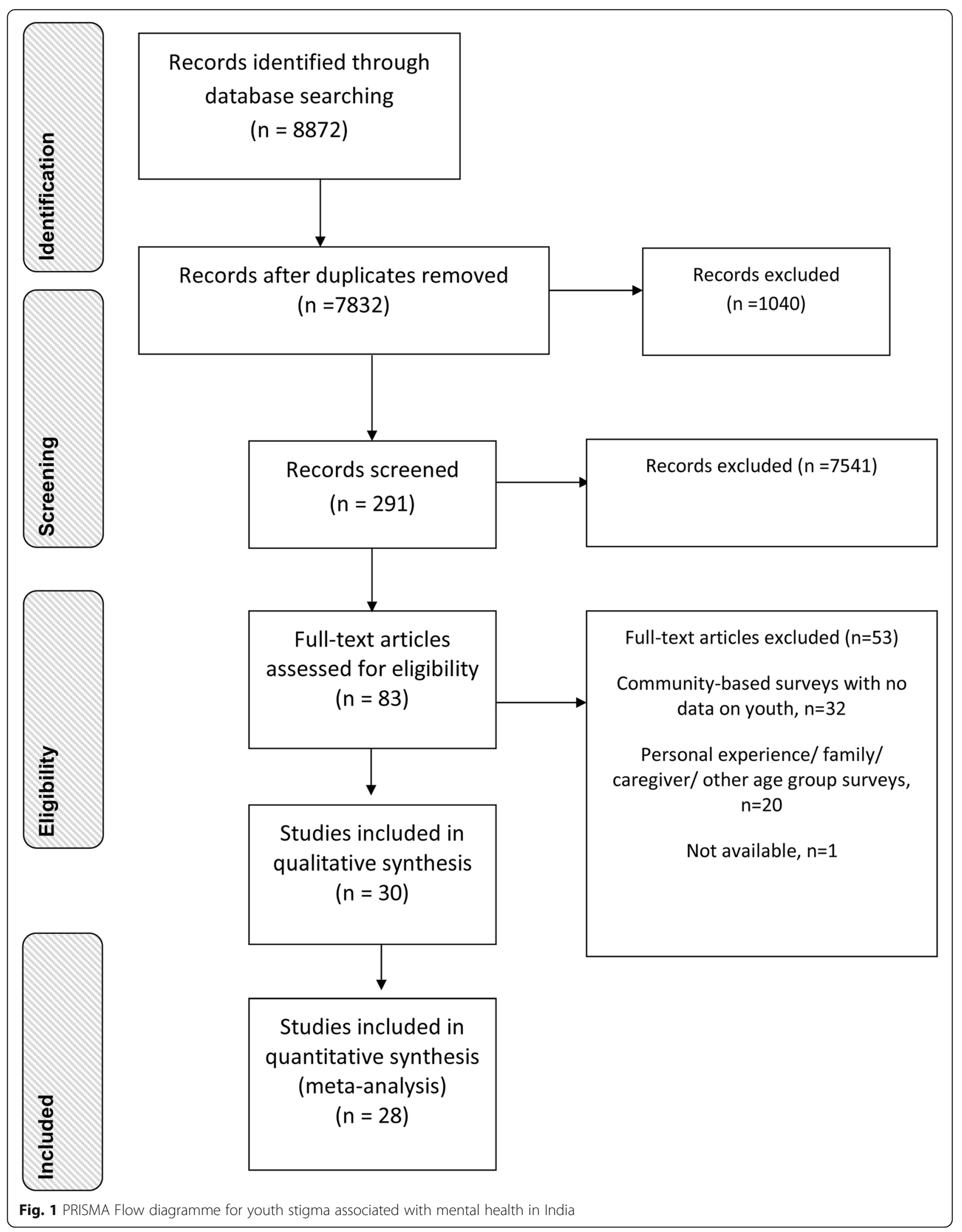




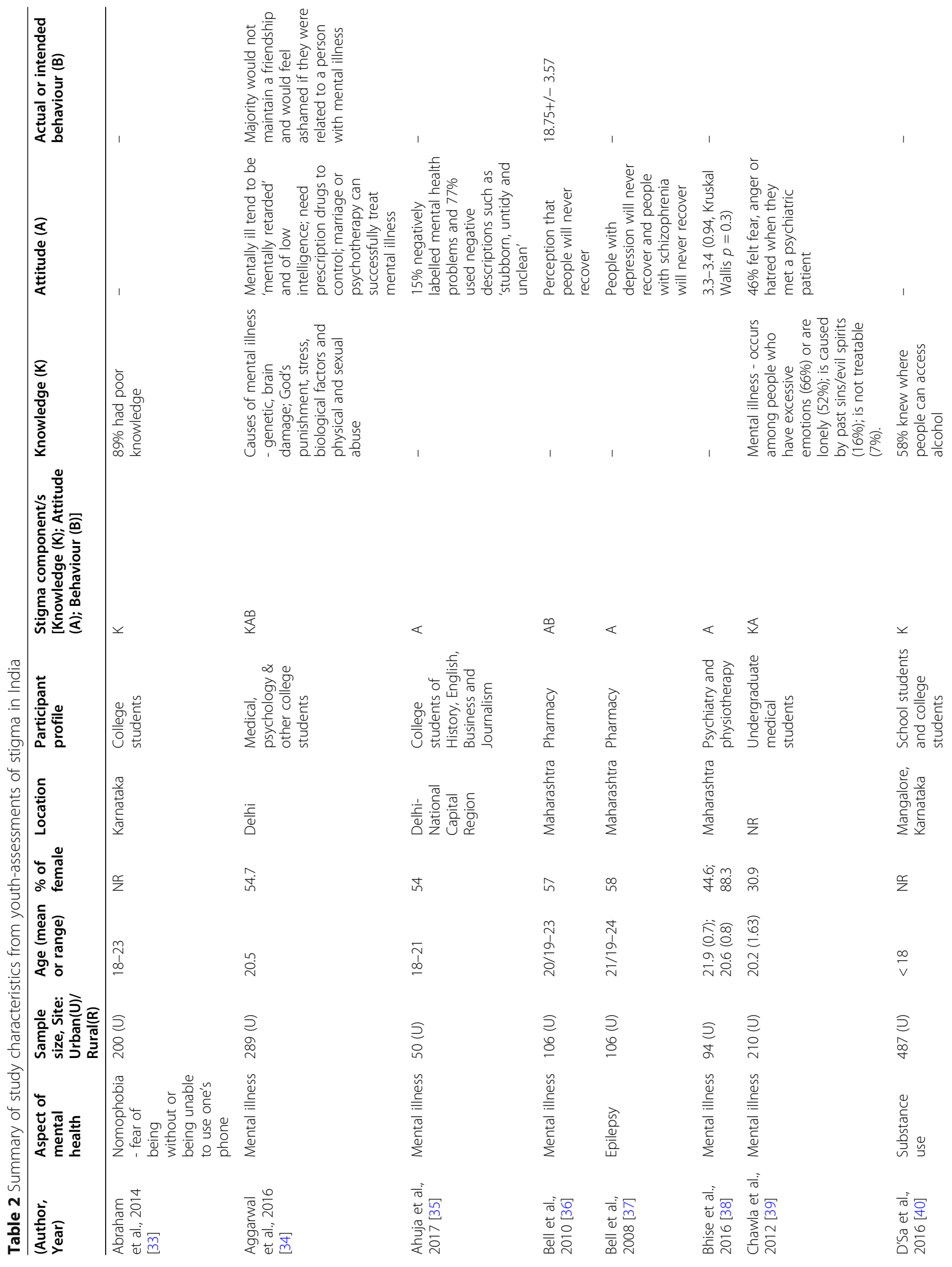




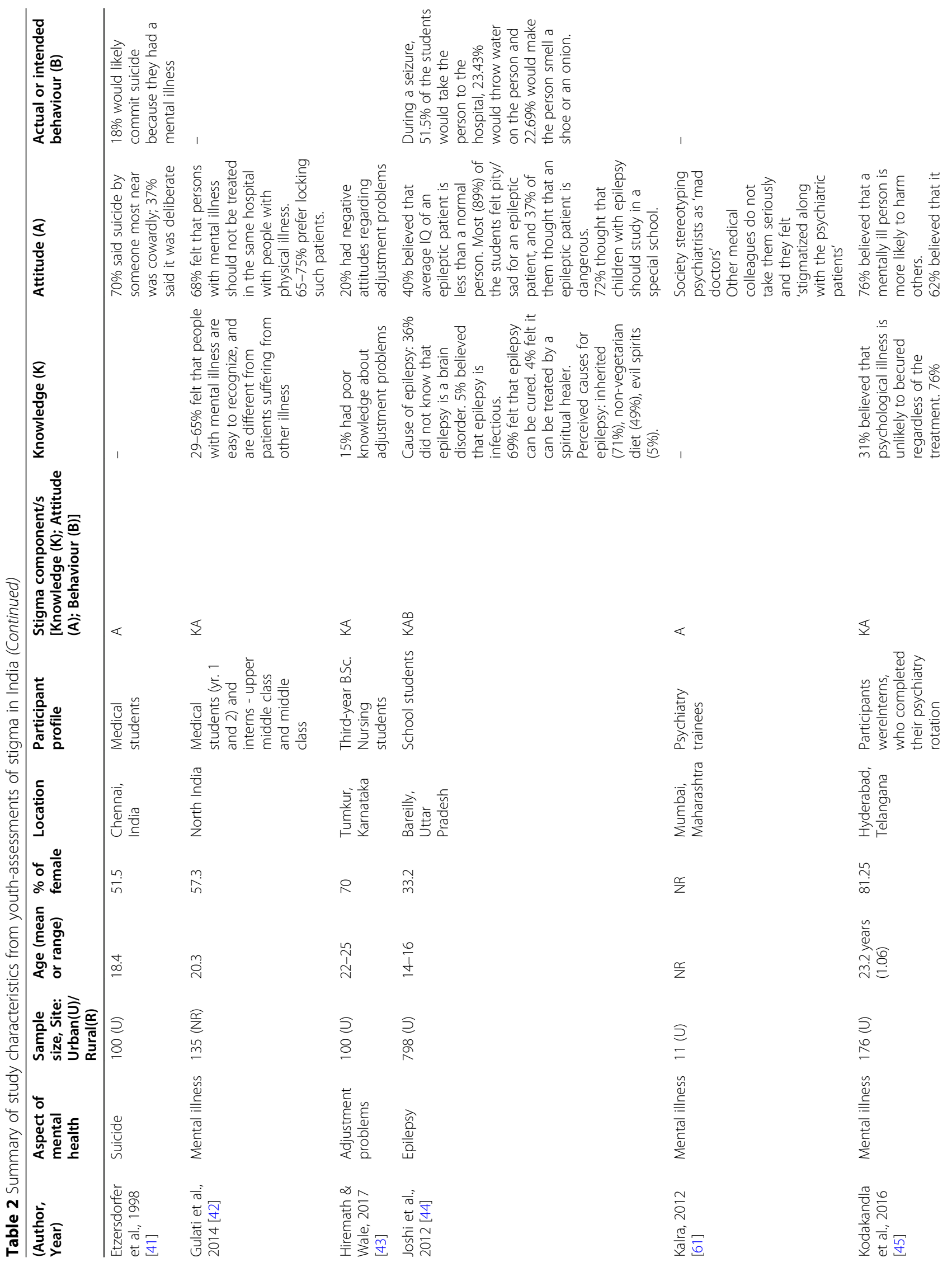




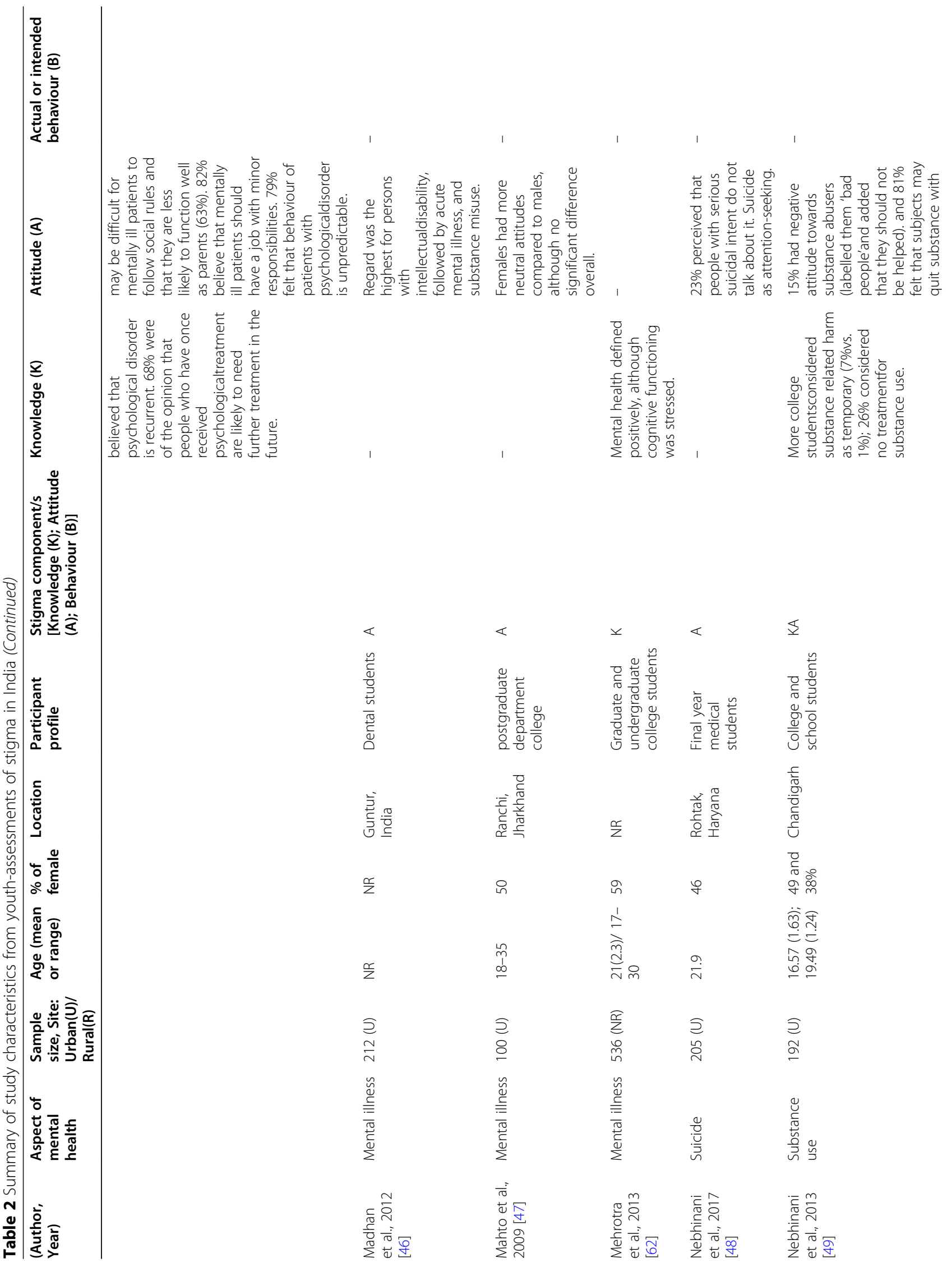




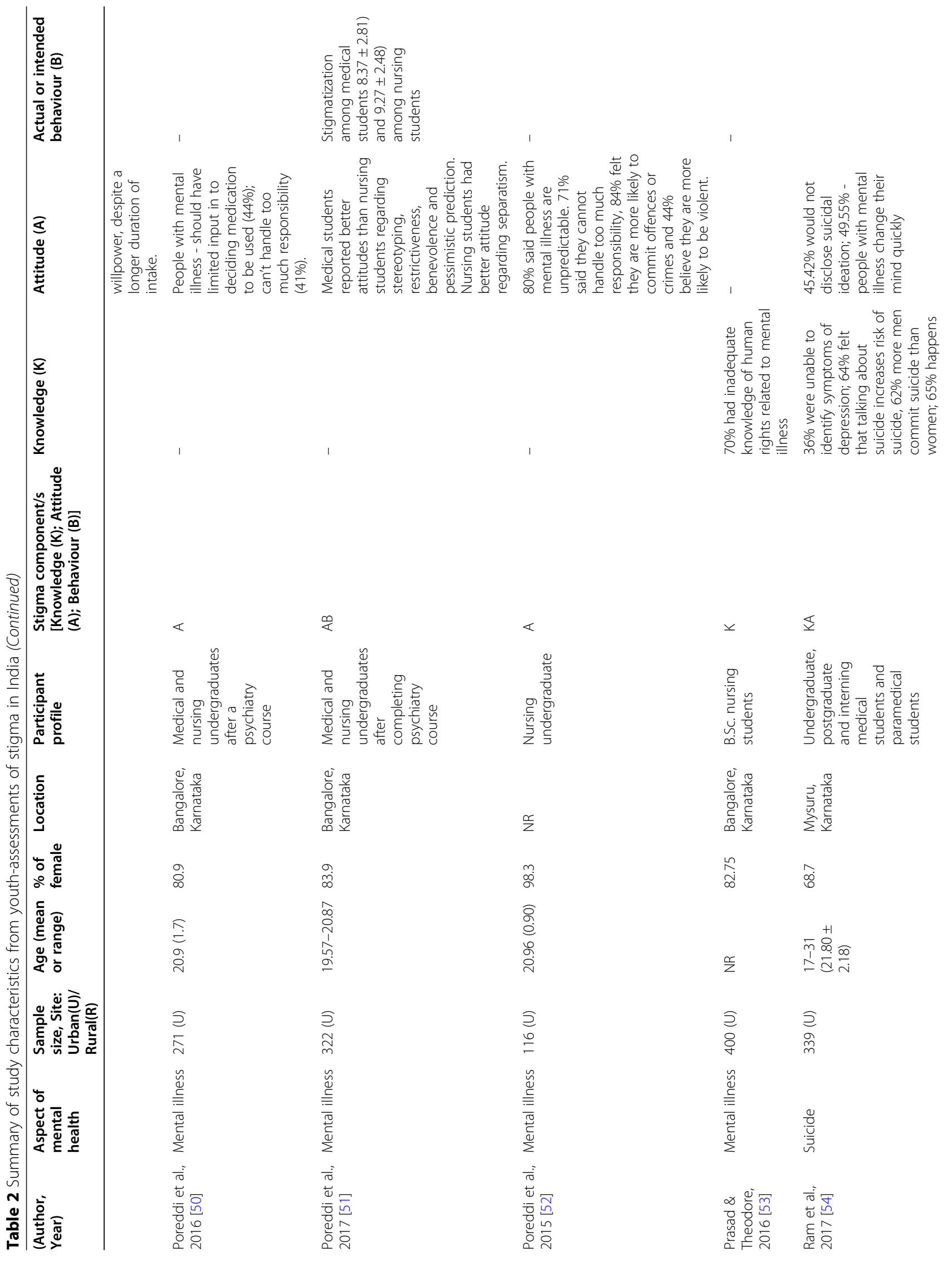




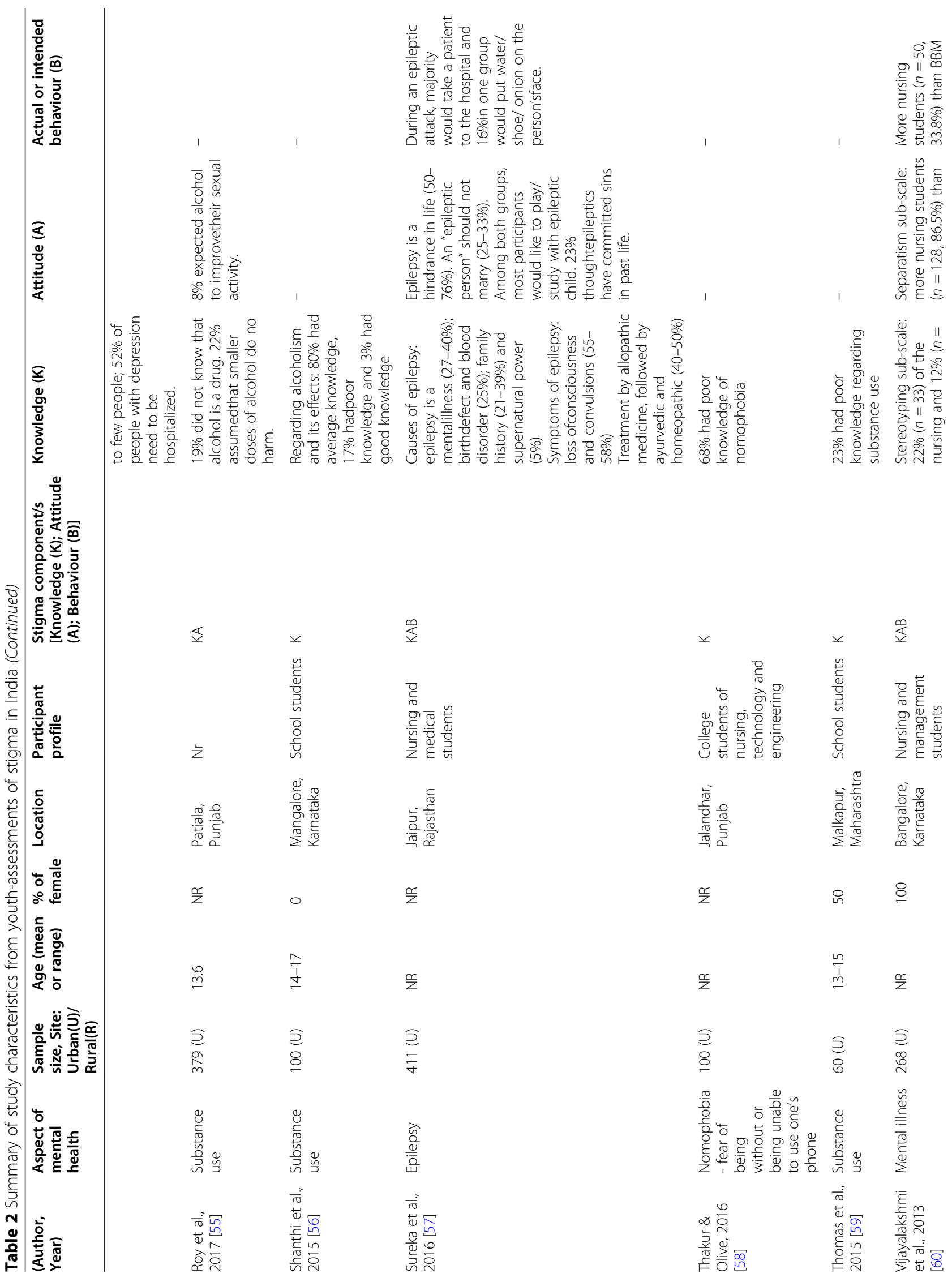




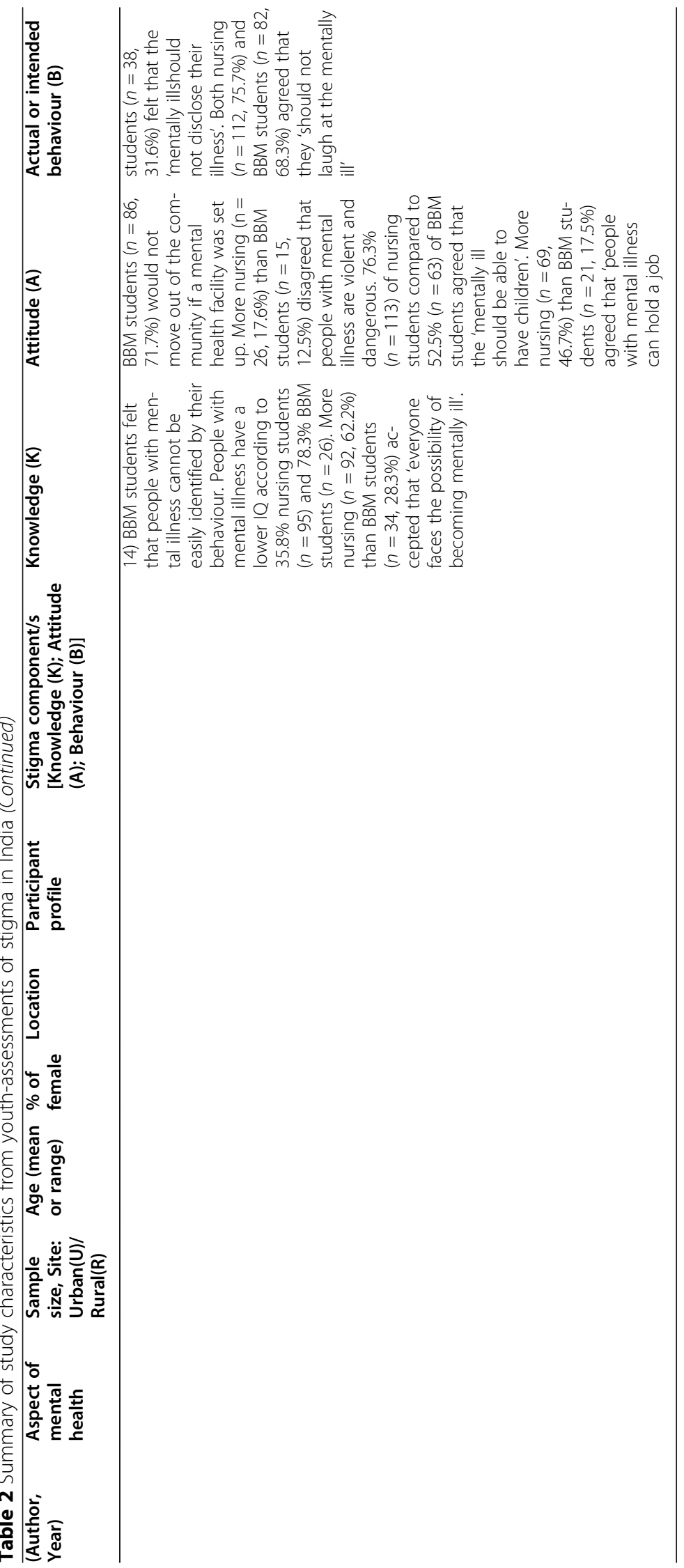




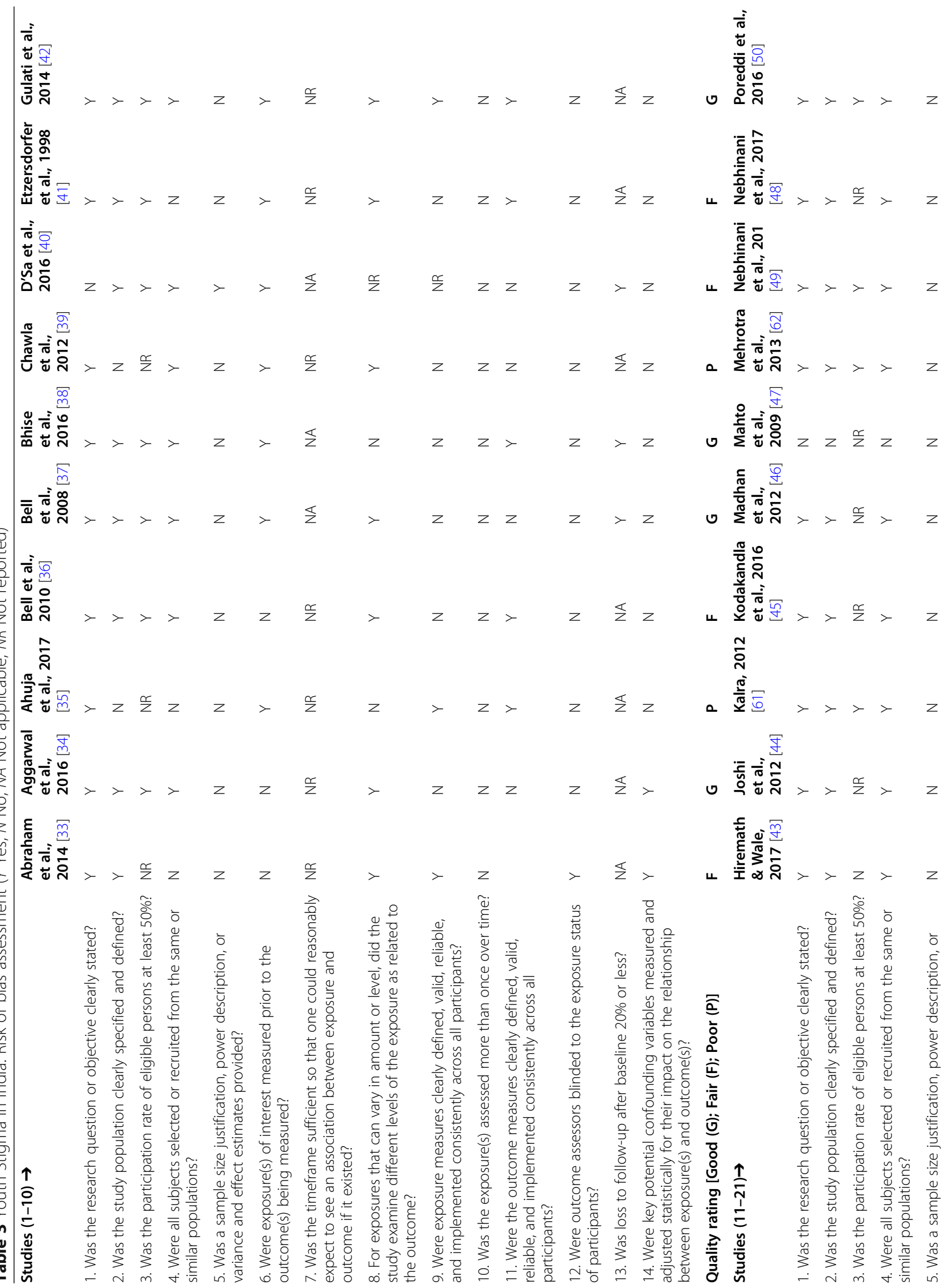




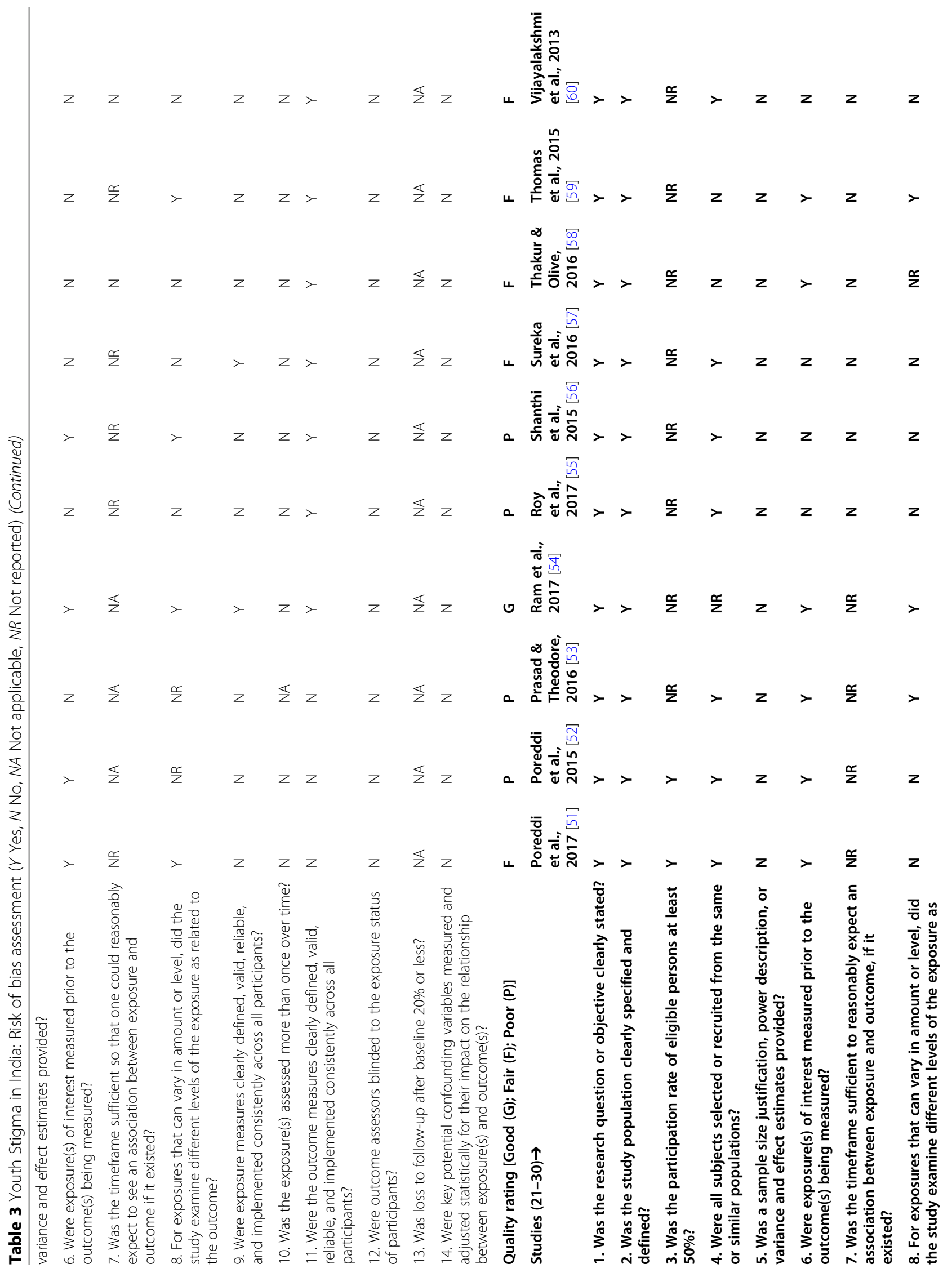




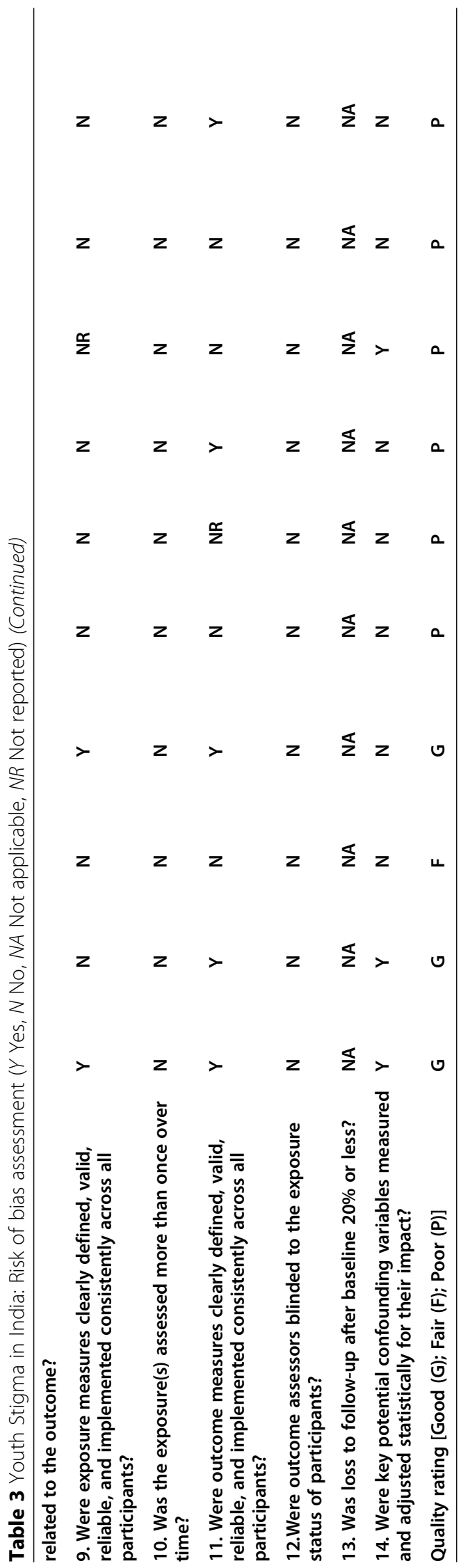




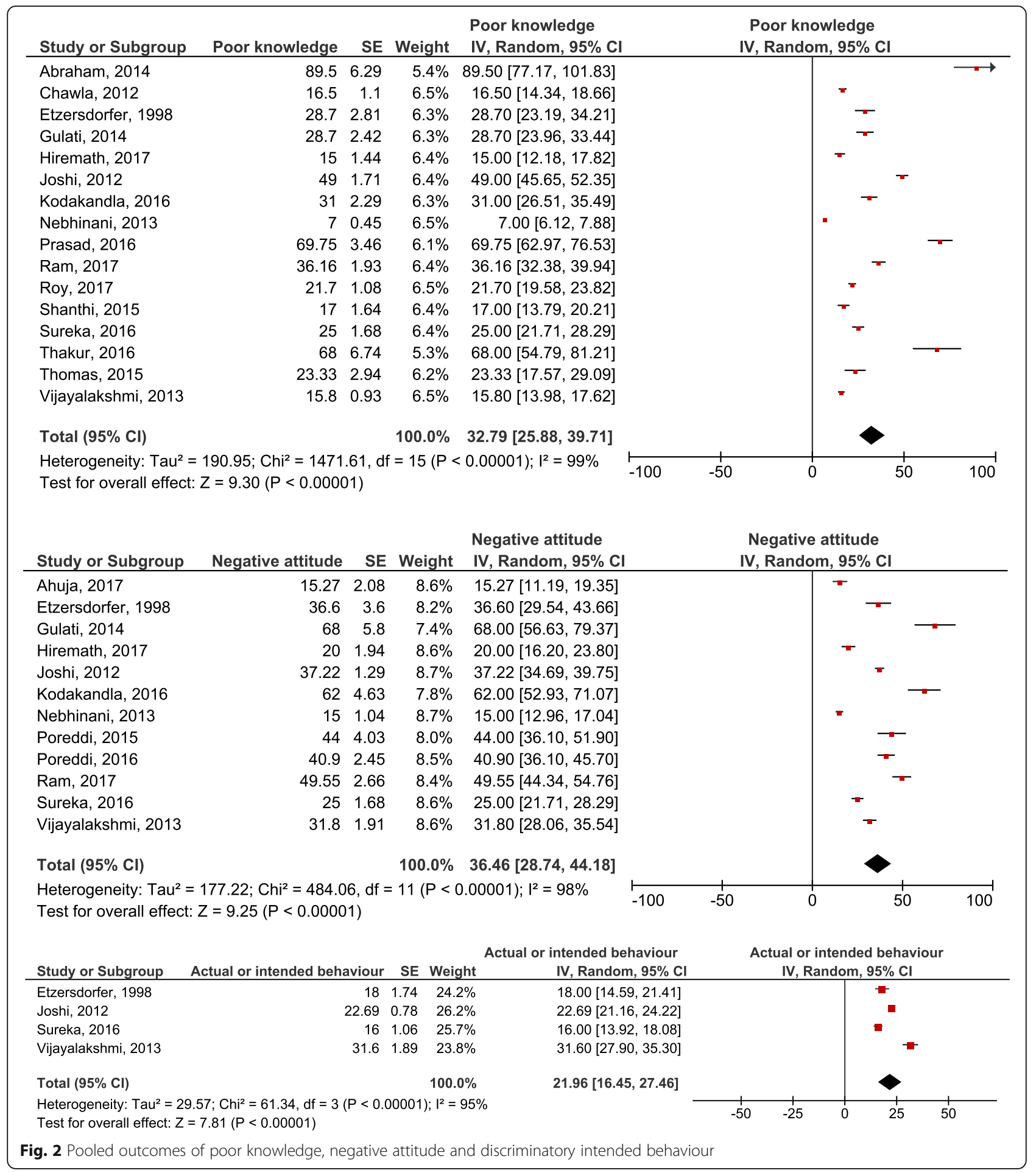

ayurvedic and homeopathic treatment was required to treat mental illness, [57] or that control over symptoms was possible only with prescription drugs [34] or hospitalisation [54]. Youth in other included studies believed that mental illness was principally due to genetic or supernatural causes, [34, 44, 57] or believed in myths that mental illness is infectious or due to a non- vegetarian diet [44]. Only one study from the capital city, Delhi found that environmental factors such as stress, biological factors and physical and sexual abuse, were perceived causes of mental illness among youth [34]. As a result, it is plausible that believing that factors outside of one's individual and social control are responsible for mental health problems may be linked to beliefs that 
Table 4 Characterizing mental-health-related public stigma: common conceptual gaps and perceptions among Indian youth

\begin{tabular}{|c|c|c|c|c|}
\hline $\begin{array}{l}\text { Component of } \\
\text { stigma }\end{array}$ & Themes and sub-themes & $\begin{array}{l}\text { Frequency of the theme } \\
\text { in study results }(\leq 2=\text { Small }(S) \text {, } \\
3-5=\text { Medium, }>6=\text { High })\end{array}$ & $\begin{array}{l}\text { Number of studies } \\
\text { reporting on the } \\
\text { theme in results }\end{array}$ & $\begin{array}{l}\text { Included in the } \\
\text { discussion }\end{array}$ \\
\hline \multirow[t]{35}{*}{ Knowledge } & $\begin{array}{l}\text { Symptoms/ expected behaviour of a person with } \\
\text { a mental illness }\end{array}$ & $\mathrm{H}$ & \multirow[t]{11}{*}{$\begin{array}{l}8[34,42,44,45,52,54 \\
60,62]\end{array}$} & \multirow[t]{11}{*}{$2[45,52]$} \\
\hline & Low I.Q. & M & & \\
\hline & Difficult to identify & M & & \\
\hline & Likely to harm others/ violent & M & & \\
\hline & Unpredictable behaviour & $S$ & & \\
\hline & Withdrawn/ passive & $\mathrm{S}$ & & \\
\hline & Unable to manage emotions & $S$ & & \\
\hline & Life satisfaction & $\mathrm{S}$ & & \\
\hline & Speak differently & $S$ & & \\
\hline & Differences in sleeping, eating and memory & $\mathrm{S}$ & & \\
\hline & Multiple personalities associated with depression & $S$ & & \\
\hline & Treatment and recovery & $\mathrm{H}$ & \multirow{5}{*}{$\begin{array}{l}7[34,36,37,44,45,54 \\
57]\end{array}$} & \multirow[t]{5}{*}{$4[34,36,44,57]$} \\
\hline & Unlikely to be cured (recurrent, lifelong) & M & & \\
\hline & Marriage as a social intervention & M & & \\
\hline & Treatment by a spiritual healer & $\mathrm{S}$ & & \\
\hline & $\begin{array}{l}\text { Heavy/ multiple medication/ hospitalisation } \\
\text { needed }\end{array}$ & $\mathrm{S}$ & & \\
\hline & Causes of mental illness & $\mathrm{H}$ & \multirow[t]{9}{*}{$3[34,44,57]$} & \multirow{9}{*}{$\begin{array}{l}5[34,42,44,57, \\
62]\end{array}$} \\
\hline & Genetic/ hereditary/ birth defect & M & & \\
\hline & Evil spirits and bad deeds & M & & \\
\hline & Brain damage & $\mathrm{S}$ & & \\
\hline & Stress & $\mathrm{S}$ & & \\
\hline & Social environment & $S$ & & \\
\hline & Infectious transmission & $\mathrm{S}$ & & \\
\hline & Physical/ sexual abuse & $S$ & & \\
\hline & Non-vegetarian diet & $\mathrm{S}$ & & \\
\hline & Alcohol and its effects & M & \multirow[t]{6}{*}{$4[40,49,55,56]$} & \multirow[t]{6}{*}{$3[40,49,55]$} \\
\hline & Associated with temporary harm & M & & \\
\hline & Locations to access & S & & \\
\hline & Prevalence of youth substance use & $\mathrm{S}$ & & \\
\hline & Treatment/ cessation services & $\mathrm{S}$ & & \\
\hline & Associated with suicide & $\mathrm{S}$ & & \\
\hline & Can happen to anyone & $\mathrm{S}$ & \multirow[t]{4}{*}{$2[54,60]$} & \multirow[t]{4}{*}{-} \\
\hline & Mental illness can happen to anyone & $\mathrm{S}$ & & \\
\hline & Suicide happens to few people & $S$ & & \\
\hline & Suicide occurs more among women & $S$ & & \\
\hline \multirow[t]{4}{*}{ Attitude } & $\begin{array}{l}\text { Cannot shoulder responsibility or take life } \\
\text { decisions }\end{array}$ & $\mathrm{H}$ & \multirow[t]{4}{*}{$6[34,45,50,52,57,60]$} & \multirow[t]{4}{*}{$\begin{array}{l}7[34,42,45,50, \\
52,57,60]\end{array}$} \\
\hline & Should not marry or should be married & & & \\
\hline & Unlikely to be good parents & $\mathrm{S}$ & & \\
\hline & Unable/ incapable of having a job & $S$ & & \\
\hline
\end{tabular}


Table 4 Characterizing mental-health-related public stigma: common conceptual gaps and perceptions among Indian youth (Continued)

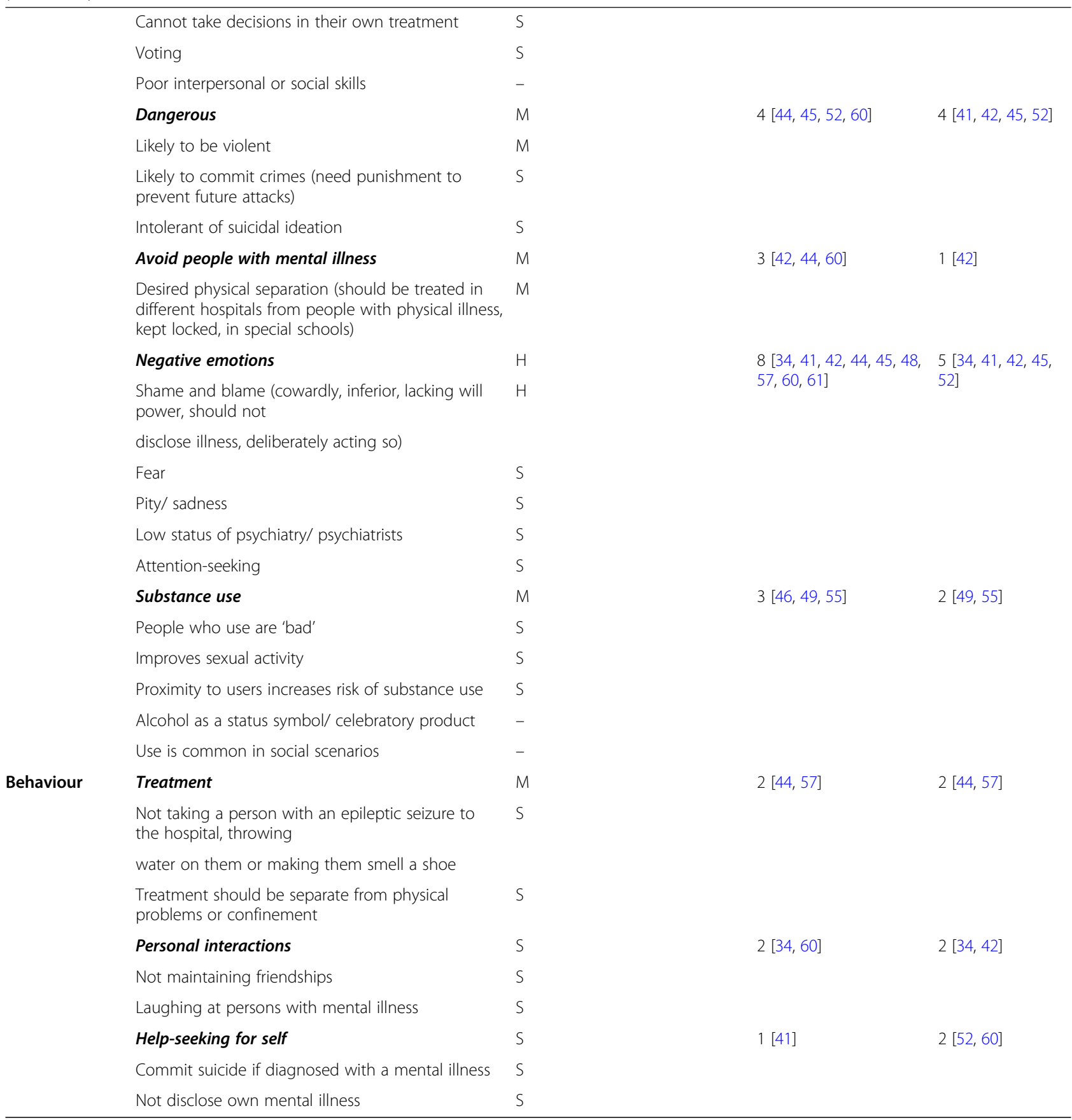

interventions to alleviate such problems are also beyond one's control. Further, although youth believed that it was easy to recognize people with mental illness when compared to people who suffer from other physical illnesses, $[42,60]$ they were not able to correctly identify symptoms of mental health problems in any studies (including linking alcohol with only temporarily harmful effects) $[49,54-56]$.

\section{Attitude}

Negative perceptions that people living with mental illness are unable to control the problem, and are likely to be dangerous, violent, criminal or unpredictable was held by more than $70 \%$ of youth in four studies reporting these outcomes $[44,45,52,60]$. Beliefs that people with mental illness are cowards, [41] lack willpower, [49] are difficult to like [64] and are to blame for their 
problems [36, 37] were found in several studies. Other studies found that people with mental illness were assumed to be less intelligent than others, $[44,60]$ or be prone to changing their mind quickly [54]. In a study, suicide was perceived as a cowardly act by $70 \%$ of youth, $29 \%$ said it was impulsive and 36\% said it was deliberate [41]. Talking about suicide was perceived to increase the risk of suicide [54] and since youth believed that people who are serious about suicide do not talk about it, [48] youth would likely find it difficult to communicate about such problems and brush aside disclosure of suicidal intent. In contrast, $89 \%$ of the students felt pity for an epileptic patient in one study [44]. A study showed that attitudes were most positive towards people with intellectual disability, and less favourable to people with acute mental illness, and least of all towards people who were associated with substance misuse [46]. Where substance use was involved, people with mental illness were labelled 'bad' and were expected to overcome their problem through will power [49].

The responsibility of work and social roles was deemed too difficult for people with mental illness by $41 \%$, [52] 71\% [50] and 63\% [45] of youth in three studies. A study suggested that youth believed that people with mental illness could only be given work with minor responsibilities [45]. However, youth were divided between whether people with mental illness should get married and have children, as a form of treatment of their illness. In another study nursing students felt that mental illness was a strong ground for divorce compared to business management students, although business management students held significantly more stigmatising views than nursing students on whether people with mental illness should have children and hold a job [60]. Overall, studies show that youth were unaccepting of the autonomy and independence of theose suffering from mental illness and did not consider them capable of managing their personal and professional life.

\section{Intended behaviour}

Social distance [36] and stigmatisation [51] were likely behaviours of Indian youth towards people with mental health problems. Most youth in studies preferred to exclude people with mental health problems from treatment-related decision-making [50] and education [44]. In one study, between 25 and $40 \%$ of health professionals in-training believed that people with mental health problems need to be separated from others with physical illnesses for treatment [42]. Youth in a study would prefer to lock up or punish people with mental illness, out of fear of being attacked [42]. A third of business management students were significantly more likely to move out of a neighbourhood if a mental health facility was set up compared to nursing students [60].
About $48.5 \%$ of students in a study would not take a person suffering from a seizure to the hospital [44]. Unusual and shame-inducing practices, such as making the person smell a shoe or an onion, were associated with likely behaviours of youth towards a person going through an epileptic attack $[44,57]$. Youth in two studies preferred not to disclose mental illness, [41, 60] with nearly $20 \%$ of youth in one study reporting that they would likely commit suicide if they developed a mental disorder [41]. However, in one study youth believed that feeding and keeping people with mental illness comfortable, equivalent to 'throwing money at the problem,' was not enough [42].

\section{Recommendations to reduce youth mental health stigma in India}

Content and terminology

Most studies identify the need for interventions to sensitize students about potential causes, treatment effectiveness and duration, and abilities of people living with mental illness [33, 34, 44, 46, 50, 55, 57, 60, 62]. A study suggested that using lay language and commonplace perspectives on mental health and communitybased interventions may aid in reaching more youth [62]. Moreover, the use of bio-medical explanations and terms was found to intensify discriminatory attitudes $[62,65]$. Studies by Bell emphasize that the authors made assumptions that a common understanding of schizophrenia and severe depression exists, whereas participants may have understood survey instruments differently [37]. Finally, a study also hypothesized that emphasizing mental 'fitness' or wellbeing as a goal of mental health promotion may be more appealing and acceptable to youth [62].

\section{Integrating with educational curriculum}

Information campaigns targeting youth and the general public are emphasised as a key step towards reducing mental health stigma [44, 45, 49]. Public health awareness programs that use a broad, behaviour-focused approach were recommended to improve suicide and depression literacy [54]. As many studies in this review evaluate the level of stigma among health professionals in-training, enhancing educational curriculum, professional ethics and code of conduct, awareness camps and clinical training for improved treatment and care practise are advocated $[38,42,45,52,57,61]$. Some strategies to inculcate positive attitudes among medical and nursing students include: short educational interventions, [51] participation by consumers, [66] and use of role play and entertainment-education techniques [43]. In educational settings, recommended initiatives to reduce stigma include: continuous and repetitive educational efforts in partnership with parents and teachers, 
[44] reaching students who are not necessarily in direct contact with mental illness, [60] and lectures, media and wider campaigns about treatment of substance abuse [49]. Further, youth volunteering in activities or programs related to mental health may help them to build skills in mastering their environment [62].

\section{Discussion}

The most notable gap related to knowledge of mental health problems among young people in India was that all such problems were considered to be acute, severe or serious and therefore, people with such problems are perceived as dangerous or unable to manage their daily life or function as per societal roles and norms. Although US and Latin American youth perceive people with mental health problems as more dangerous if they associated these problems with genetic causes or biological reasons, [16, 23] Indian youth lack knowledge about causes and largely associated such problems with functional impediments and believed that limited/no treatment exists for such problems. Next, young people in included studies were both unable to identify common symptoms or use a common term or psychiatric label to describe symptoms. Consequently, young people in India may not consider themselves vulnerable to acute problems or recognise every day mental health problems when they experience them. Similar to a crosssectional survey of public stigma among 15-60 year old Indians, [67] this review found that neither symptoms nor psychiatric labels nor mental illness (broadly) are widely recognized or understood. Since different expressions and thresholds for accepting symptoms of mental health problems may lead to such problems often going unnoticed $[10,68]$ and since psychiatric labels may potentially induce prejudice (e.g. 'depressed' was self-rated as derogatory), [69] there is a need for culture-specific explanatory models of mental illness or use of culturallyappropriate vignettes instead of focusing on psychiatric labels to aid young people in recognizing mental health problems from an early age, in both stigma-assessment research questionnaires [70] and anti-stigma communication strategies $[7,71,72]$.

Recommendations to reduce stigma by studies in this review include implementation of de-stigmatization and information-sharing interventions to build awareness and sensitize youth about mental health problems. Unlike, high income countries with national mental health education and promotion campaigns, such as the Time to Change campaign, [73] and Headspace, [74] India has no such country-wide mental health awareness campaign. Recent anti-stigma programmes involve university students in peer-led educational components as in the Active Minds and University Bring Change to Mind programmes $[75,76]$. A community-based anti-stigma campaign in India improved attitudes and intended behaviour towards people with mental health problems; however, it lacked a control group and targeted people above 18 years of age [77]. In the future, such interventions may be adapted to appeal to young people to address their age-appropriate needs and communication issues. Thus, future anti-stigma interventions should integrate with the education system, use interactive/ visual media and focus on mental health problems broadly, by defining and explaining symptoms through relevant vignettes or stories, rather than using psychiatric labels for specific disorders or illness.

This review shows that public stigma among youth in India has similar characteristics to public stigma in other cultures. Studies in this review show that Indian youth expressed fear, shame, sadness, pity or sympathy, similar to global attitudinal responses of 'stigmatisers.' [78] As in studies from Lebanon, [79] Singapore [13] and China, [80] evil spirits and God's punishment were important determinants of public stigma in India relative to environmental factors. Similar to adolescents in Greece, [81] Indian youth believed that mental health problems were easily identifiable and that people with such problems appeared markedly different. We also find that considerable youth believe in both traditional/faith healers and psychiatry as part of India's pluralistic medical system [82, 83]. Additionally, our findings resonate with other studies that marriage and child-bearing are important life events, which represent social worth in Indian and Asian culture, [84-86] unlike in Western countries [7], but Indian cultures likely differ from the West in that autonomy, decision-making and capability of young people with mental health problems are overruled by adults. Further, culture may alter how participants perceive mental health problems, for example, alcohol consumption may not be perceived as harmful because of traditionally acceptable use of some addictive substances (e.g. betel nut) in India.

Potential factors that likely exacerbate stigma in India are that people in Asian cultures accept and observe status inequality more readily, [87] and youth seek to satisfy adults and echo the views of their families; a collectivist identity, where people fear what that others know about their problems [88] and gender inequality, since global studies report higher social distance among females than males [89-91]. Thus, despite the belief that Indian culture has protective, cohesive family environments which has the potential to readily accept those suffering from with mental health problems, [68] mental-health-related stigma persists. A study of 11 countries comparing how stigma operates in the East and West found that 'deep cultural concerns about how being diagnosed with a mental illness would impact family members,' social and economic status,' fear of disclosure and moral 
attributions affected stigmatizing attitudes in Eastern countries [92]. Such findings may also apply to youth in India and other low- and middle-income countries where there is a lack of understanding about stress and mental health issues, which then interact with other issues such as coping with poverty, in addition to strong cultural beliefs.

\section{Strengths and limitations}

This is the first systematic review to collate findings from mental -health -related stigma studies focused on youth in India. There are no other country-specific, youth-focused systematic reviews and meta-analyses on public stigma. The approach of assessing the magnitude of stigma and method developed are also unique to this review. This review outlines the evidence for an ageappropriate educational response to reducing public stigma in India, in three key ways: (i) quantifying the problem and the rationale for change; (ii) identifying and characterizing common gaps in knowledge, attitude and behaviour that require counter-messages; and (iii) synthesizing strategies to reduce public stigma. By applying the method used in this review, future studies may compare characteristics of youth stigmatization of people with mental health problems across countries and cultures. We believe that lectures, talks and discussions suggested by studies in this review may work for health professionals in-training, who develop stigma in a unique way, [93] however, alternative approaches will be required to engage students pursuing other disciplines who lack exposure to information about mental health problems and could have perhaps not previously encountered a person with a mental health problem. Such approaches must focus overtly on challenging stereotypes, by including more visual-based interaction and relatable language.

Although results of the meta-analysis present a worstcase scenario, selecting negative responses only, it highlights the magnitude of mental -health -related stigma and the need for intervention among youth in India. Potential reasons for high heterogeneity among pooled studies include varying definitions or terms, a range of assessment measures to gauge stigma and use of nonstandard data collection procedures. Given the limited number of studies providing adequate information on stigma, it was not feasible to assess whether stigma associated with particular disorders/conditions was similar to that of stigma associated with mental illness more generally or other disorders. As more than half of the included studies had a fair risk of bias and pooled data showed high heterogeneity, the review findings are unlikely to be valid among youth in other settings in India. Further, a lack of studies among school-going adolescents skew our results towards college youth and particularly, health professionals in-training. The quality of stigma-related studies may be improved in future cross-sectional studies through randomised sampling and sample size estimation, use of validated instruments and improved reporting. Due to lack of age-segregated data in community-based knowledge, attitude, behaviour-assessment studies, a comparison between the level of public stigma between Indian youth and adults was not feasible. As studies in this review were skewed by geography and population groups, it was not feasible to identify specific youth groups or regions which could be targeted to reduce public stigma. In addition, since most studies used survey instruments designed for adults, marriage and child-bearing find greater mention than education, employment, friendships or other youthrelevant milestones. Finally, one article was unavailable for inclusion in this systematic review.

To update this review with the most recent studies, we conducted the search strategy in PubMed and CINA HL+ (for the period September 2018-2020). Since 2018, we found six additional studies (including two that were previously unavailable), all of which support findings presented in this review. A quantitative study using a new scale found 18-24 year-old Indians' attitudes to suicide as negative, and that they felt suicide could not be prevented and that there were no risk signs [94]. Two other studies found poor levels of knowledge, with one study showing that $53.7 \%$ of students had poor knowledge regarding preventive measures of suicidal behaviour [95] and another showing that $43 \%$ of school students had inadequate knowledge of substance use [96]. Another study found that medical interns agreed that 'patients like this (with psychiatric illnesses) irritate me' or treating them was a 'waste of money.' [97] A qualitative study echoed our findings that mental health and mental illness were unclear concepts and were associated with acute problems, such as 'brain deficiency or dysfunction and abnormal behaviour.' [98] Another qualitative study found that college students believed that using substances helped to relieve depression, enhance health and lose weight and that using in small quantities did not cause harm [99]. The study suggests that future interventions should be non-judgemental, student-friendly, relatable and 'specific to the youth's life circumstances and needs.'

Notably, updating the systematic review also highlighted several studies that contribute to the social context of mental-health-related stigma. A qualitative study of community stakeholder perspectives (not including youth) described that schools are hesitant to acknowledge the extent of mental health problems and students fear being labelled, thereby creating an environment of hiding mental health problems [100]. The study also highlighted the need for school and college counsellors and mental health training 
for teachers. Our review includes studies on nomophobia, an emerging mental health issue, which is echoed by contextual studies that finding increasing rates of substance use and technology addiction among youth due to urbanization in India [101]. Other studies focused on measuring prevalence, progression perceived harms of various disorders and conditions, including depression, anxiety and stress, [102, 103] alcohol use, [104, 105] body image disorders $[106,107]$ and aggression, bullying and violence, [108] and correlates such as parental pressure to perform academically, [109, 110], relationships, negative peer pressure, school environment and gender roles [110]. [111].

\section{Conclusions}

India is home to a third of the world's youth. Mental health problems are likely to adversely impact the productivity and capabilities of India's youth. Among youth included in this review, one-third had poor knowledge and negative attitudes, and one-fifth intended to or had actually discriminated against a person with mental illness. Although most of these studies were among college students, they were predominantly focused on health professionals in-training. A majority of youth potentially recognized mental health problems only if they were acute. Select aspects of traditional Indian culture, such as importance of marriage, are likely responsible for specific manifestations of stigma. Educational interventions to reduce stigma associated with mental health may improve help-seeking behaviours by avoiding the use of psychiatric labels that are not commonly understood, instead focus on symptomatic vignettes that may explicitly discuss a range of mental health problems with varying severity. Intervention content that directly and interactively discusses youth mental-health-stigma-related responses and age-appropriate social roles, rather than focusing on future roles such as marriage, may help to achieve timely detection of mental health disorders among youth.

\section{Supplementary Information}

The online version contains supplementary material available at https://doi. org/10.1186/s12888-020-02937-x.

\section{Additional file 1.}

\section{Abbreviations}

PRISMA: Preferred reporting items for systematic reviews and meta-analyses; SE: Standard error: Cl: Confidence interval; ESRC: Economic and social research council; K: Knowledge; A: Attitude; B: Behaviour

\section{Acknowledgements}

Not applicable.

\section{Authors' contributions}

SMG and TTS conceptualized the study purpose and method. SMG searched all databases, and jointly reviewed inclusion of studies with MP through discussion. SMG extracted relevant data and wrote the manuscript with support from TTS and MP, who also helped supervise the project. TTS and MP provided detailed comments and edited the manuscript. MK and UR provided guidance on aspects of the Indian context, conceptualization of stigma and contributed by editing the manuscript. All authors read and approved the final manuscript.

\section{Authors' information}

SMG - Since completion of this study, the first author has started a postdoctoral research fellowship in adolescent mental health promotion and substance use prevention. Prior to this study, the author developed and led a pilot nationwide campaign to raise awareness about mental health problems, with specific activities involving youth. These activities were implemented in partnership with the National Mental Health Programme, Government of India. The author was motivated to conduct this study due to the lack of evidence about the gaps related to public stigma amongst youth in India and need for evidence-based educational interventions in India.

\section{Funding}

This work was supported by a Wellcome Trust Capacity Strengthening Strategic Award to the Public Health Foundation of India and a consortium of UK universities. The content is solely the responsibility of the authors and does not represent the views of the funding organization.

\section{Availability of data and materials}

The data supporting the conclusions of this article are included within the article tables and figures.

\section{Ethics approval and consent to participate}

Ethics approval for this study was received from both the London School of Hygiene and Tropical Medicine Ethics Committee and Institutional Ethics Committee - Indian Institute of Public Health Hyderabad.

\section{Consent for publication}

Not applicable.

\section{Competing interests}

The authors declare that they have no conflict of interest or competing interests.

\section{Author details}

${ }^{1}$ Indian Institute of Public Health- Hyderabad, Public Health Foundation of India, Hyderabad, India. ${ }^{2}$ Department of Public Health, Environments and Society, Faculty of Public Health and Policy, London School of Hygiene and Tropical Medicine, London, UK. ${ }^{3}$ Centre for Global Mental Health, Institute of Psychiatry, Psychology and Neuroscience, King's College, London, UK. ${ }^{4}$ Health Service and Population Research Department, Institute of Psychiatry,

Psychology and Neuroscience, King's College, London, UK. ${ }^{5}$ Department of Communication, Sarojini Naidu School of Arts \& Communication, University of Hyderabad, Hyderabad, India.

Received: 30 January 2020 Accepted: 28 October 2020

Published online: 16 November 2020

\section{References}

1. World Health Organization. Adolescence: a period needing special attention - Recognizing adolescence 2014 [Available from: https://apps.who.int/ adolescent/second-decade/section2/page1/recognizing-adolescence.html.

2. World Health Organization. The world health report: 2001 - mental health: new understanding, new hope. Geneva: World Health Organization; 2001.

3. Kessler RC, Amminger GP, Aguilar-Gaxiola S, Alonso J, Lee S, Ustun T. Age of onset of mental disorders: a review of recent literature. Curr Opin Psychiatry. 2007;20(4):359-64.

4. Clement S, Schauman O, Graham T, Maggioni F, Evans-Lacko S, Bezborodovs $\mathrm{N}$, et al. What is the impact of mental health-related stigma on help-seeking? A systematic review of quantitative and qualitative studies. Psychol Med. 2015;45(1):11-27.

5. Schomerus G, Angermeyer MC. Stigma and its impact on help-seeking for mental disorders: what do we know? Epidemiol Psichiatr Soc. 2008;17(1):31-7. 
6. Yang LH, Kleinman A, Link BG, Phelan JC, Lee S, Good B. Culture and stigma: adding moral experience to stigma theory. Soc Sci Med. 2007;64(7): 1524-35.

7. Koschorke M, Evans-Lacko S, Sartorius N, Thornicroft G. Stigma in different cultures. In: InThe Stigma of Mental IIIness-End of the Story? Cham: Springer; 2017. p. 67-82.

8. Thornicroft G, Brohan E, Kassam A, Lewis-Holmes E. Reducing stigma and discrimination: candidate interventions. Int J Ment Heal Syst. 2008:22(1):3.

9. Gururaj G, Varghese M, Benegal V, Rao GN, Pathak K, Singh LK, et al. National Mental Health Survey of India, 2015-16. In: NIMHANS, editor. Bengaluru: NIMHANS Publication; 2016.

10. Shidhaye R, Kermode M. Stigma and discrimination as a barrier to mental health service utilization in India. Int Health. 2013;5(1):6-8.

11. Mukolo A, Heflinger CA, Wallston KA. The stigma of childhood mental disorders: a conceptual framework. J Am Acad Child Adolesc Psychiatry. 2010;49(2):92-103.

12. Hinshaw SP. The stigmatization of mental illness in children and parents: developmental issues, family concerns, and research needs. J Child Psychol Psychiatry. 2005;46(7):714-34

13. Pang S, Liu J, Mahesh M, Chua BY, Shahwan S, Lee SP, et al. Stigma among Singaporean youth: a cross-sectional study on adolescent attitudes towards serious mental illness and social tolerance in a multiethnic population. BMJ Open. 2017;7(10):e016432.

14. Pescosolido BA. Culture, children, and mental health treatment: special section on the National Stigma Study-Children. Psychiatr Serv. 2007:58(5): 611-2.

15. Collins RL, Roth E, Cerully JL, Wong EC. Beliefs Related to Mental Illness Stigma Among California Young Adults. Santa Monica: RAND Corporation; 2014. https://www.rand.org/pubs/research_reports/RR819.html.

16. Martin JK, Pescosolido BA, Olafsdottir S, McLeod JD. The construction of fear: Americans' preferences for social distance from children and adolescents with mental health problems. J Health Soc Behav. 2007:48:50-67.

17. Gulliver A, Griffiths KM, Christensen H. Perceived barriers and facilitators to mental health help-seeking in young people: a systematic review. BMC Psychiatry. 2010;10:113

18. Kelly CM, Jorm AF, Wright A. Improving mental health literacy as a strategy to facilitate early intervention for mental disorders. Med J Aust. 2007;187(S7): S26-30.

19. Elkington KS, Hackler D, McKinnon K, Borges C, Wright ER, Wainberg ML. Perceived mental illness stigma among youth in psychiatric outpatient treatment. J Adolesc Res. 2012;27(2):290-317.

20. Parcesepe AM, Cabassa LJ. Public stigma of mental illness in the United States: a systematic literature review. Adm Policy Ment Health Ment Health Serv Res. 2013;40(5):384-99.

21. Tzouvara V, Papadopoulos C, Randhawa G. Systematic review of the prevalence of mental illness stigma within the Greek culture. Int J Soc Psychiatry. 2016;3:292-305.

22. Ando S, Yamaguchi S, Aoki Y, Thornicroft G. Review of mental-health-related stigma in Japan. Psychiatry Clin Neurosci. 2013;67(7):471-82

23. Mascayano F, Tapia T, Schilling S, Alvarado R, Tapia E, Lips W, et al. Stigma toward mental illness in Latin America and the Caribbean: a systematic review. Rev Bras Psiquiatr. 2016;38(1):73-85.

24. United Nations Population Fund. State of World Population 2014: The Power of 1.8 Billion - Adolescents, Youth and the transformation of the future. New York: United Nations Population Fund; 2014.

25. Government of India. New Pathways, New Hope: National Mental Health Policy of India New Delhi, India: Ministry of Family Welfare, Government of India (Gol); 2014

26. Ministry of Law and Justice, Government of India. The Mental Healthcare Act (Part II- Section 1). New Delhi: Controller of Publications; 2017. Date accessed: 8 Nov 2020. Available from: http://www.egazette.nic.in/ WriteReadData/2017/175248.pdf.

27. Clarivate Analytics. Endnote X7 [Computer programme]. Philadelphia: Clarivate Analytics; 2013.

28. Moher D, Liberati A, Tetzlaff J, Altman DG, The PRISMA Group. Preferred reporting items for systematic reviews and meta-analyses: the PRISMA statement. PLoS Med. 2009;6(7)e1000097.

29. National Institutes of Health. Quality assessment tool for observational cohort and cross-sectional studies Bethesda, MD: NIH; 2014 [Available from: https://www.nhlbi.nih.gov/health-pro/guidelines/in-develop/cardiovascularrisk-reduction/tools/cohort.
30. Review Manager (RevMan) [Computer programme]. Version 5.3. Copenhagen: The Nordic Cochrane Centre, The Cochrane Collaboration; 2014

31. Popay J, Roberts H, Sowden A, Petticrew M, Arai L, Rodgers M, et al. Guidance on the conduct of narrative synthesis in systematic reviews. In: Council EaSR, editor. A product from the ESRC methods programme Version2006. p. b92.

32. Sharma RR. Knowledge of psycho active substance use; disorders among college students. Nurs J India. 2001;92(2):29-30.

33. Abraham N, Mathias J, Williams S. A study to assess the knowledge and effect of Nomophobia among students of selected degree colleges in Mysore. Asian J Nurs Educ Res. 2014;4(4):421-8.

34. Aggarwal S, Singh S, Kataria D. Knowledge, attitude and social distance practices of young undergraduates towards mental illness in India: a comparative analysis. Asian J Psychiatr. 2016;23:64-9.

35. Ahuja KK, Dhillon M, Juneja A, Sharma B. Breaking barriers: an education and contact intervention to reduce mental illness stigma among Indian college students. Psychosoc Interv. 2017;26(2):103-9.

36. Bell JS, Aaltonen SE, Airaksinen MS, Volmer D, Gharat MS, Muceniece R, et al. Determinants of mental health stigma among pharmacy students in Australia, Belgium, Estonia, Finland, India and Latvia. Int J Soc Psychiatry. 2010:56(1):3-14.

37. Bell JS, Aaltonen SE, Bronstein E, Desplenter FA, Foulon V, Vitola A, et al. Attitudes of pharmacy students toward people with mental disorders, a six country study. Pharm World Sci. 2008;30(5):595-9.

38. Bhise MC, Marwale AV, Deshmukh AS, Saoji SG. Impact of differences in psychiatry curriculum of undergraduate medical and physiotherapy students on their attitude towards psychiatry. Ind J Psychiatry. 2016;58(2):208-11.

39. Chawla JM, Balhara YP, Rajesh SS. Undergraduate medical students' attitude toward psychiatry: a cross-sectional study. Ind J Psychiatry. 2012;54(1):37.

40. D'Sa JR, Shetty S, Shahina V, Sahu S, Prabhakar S, Kundapur R, et al. Awareness of alcohol among adolescents and young adults of Mangalore. Nitte Univ J Health Sci. 2016:6(1):42-4.

41. Etzersdorfer E, Vijayakumar L, Schony W, Grausgruber A, Sonneck G. Attitudes towards suicide among medical students: comparison between Madras (India) and Vienna (Austria). Soc Psychiatry Psychiatr Epidemiol. 1998:33(3):104-10.

42. Gulati P, Das S, Chavan BS. Impact of psychiatry training on attitude of medical students toward mental illness and psychiatry. Ind J Psychiatry. 2014:56(3):271-7.

43. Hiremath LC, Wale GR. Assessment of the knowledge and attitude regarding adjustment problems among nursing students. Asian J Nurs Educ Res. 2017;7(3):423.

44. Joshi HS, Mahmood SE, Bamel A, Agarwal AK, Shaifali I. Perception of epilepsy among the urban secondary school children of Bareilly district. Ann Ind Acad Neurol. 2012;15(2):125-7.

45. Kodakandla K, Nasirabadi M, Pasha MS. Attitude of interns towards mental illness and psychiatry: a study from two medical colleges in South India. Asian J Psychiatr. 2016;22:167-73.

46. Madhan B, Gayathri H, Garhnayak L, Naik ES. Dental students' regard for patients from often-stigmatized populations: findings from an Indian dental school. J Dent Educ. 2012:76(2):210-7.

47. Mahto RK, Verma PK, Verma AN, Singh AR, Chaudhury S, Shantna K. Students' perception about mental illness. Ind Psychiatry J. 2009;18(2):92.

48. Nebhinani N, Jagtiani A, Chahal S, Nebhinani M, Gupta R. Medical students' attitude toward suicide prevention: an exploratory study from North India. Med J Dr DY Patil Univ. 2017;10(3):277-80.

49. Nebhinani N, Nebhinani M, Misra AK, Grewal S. Substance-related knowledge and attitude in school and college students. German Journal of Psychiatry. 2013;16(1):15-9.

50. Poreddi V, Gandhi S, Thimmaiah R, Suresh BM. Attitudes toward consumer involvement in mental health services: a cross-sectional survey of Indian medical and nursing undergraduates. Invest Educ Enferm. 2016;34(2):243-51

51. Poreddi $\mathrm{V}$, Thimmaiah $\mathrm{R}$, BadaMath S. Medical and nursing students' attitudes toward mental illness: an Indian perspective. Invest Educ Enferm. 2017:35(1):86-94

52. Poreddi V, Thimmaiah R, Chandra R, BadaMath S. Bachelor of nursing students' attitude towards people with mental illness and career choices in psychiatric nursing. An Indian perspective. Invest Educ Enferm. 2015;33(1):148-54.

53. Prasad MN, Theodore DD. Knowledge of nursing students regarding human rights of mentally ill. Asian J Nurs Educ Res. 2016;6(2):151-5. 
54. Ram D, Chandran S, Gowdappa B. Suicide and depression literacy among healthcare profession students in tertiary Care Center in South India. J Mood Disord. 2017;7(3):149-55.

55. Roy A, Ikonen R, Keinonen T, Kumar K. Adolescents' perceptions of alcohol Health Educ. 2017;117(3):280-96.

56. Shanthi S, D'Souza VM. Assess the knowledge of adolescents regarding alcoholism and its effects in a selected Urban School at Mangalore with a view to prepare a pamphlet. Asian J Nurs Educ Res. 2015;5(1):23-5.

57. Sureka RK, Saxena S, Rijhwani P, Chaturvedi S, Charan A. Knowledge, attitude and practice of epilepsy among undergraduate medical and nursing students in Rajasthan. J Evol Med Dent Sci Jemds. 2016;5(98):7166-9.

58. Thakur P, Olive K. A quasi experimental study to assess the effect of structured teaching Programme on knowledge regarding Nomophobia among students of selected colleges in district Jalandhar. Punjab Int Nurs Educ. 2016:8(2):119-21.

59. Thomas NL, Naregal PM, Mohite VR, Tata SH, Karale RB, Kakade SV Effectiveness of role play on knowledge of adolescents regarding substance abuse. J Krishna Inst Med Sci Univ. 2015;4(2):114-21.

60. Vijayalakshmi P, Reddy D, Math SB, Thimmaiah R. Attitudes of undergraduates towards mental illness: a comparison between nursing and business management students in India. S Afr J Psychiatry. 2013;19(3):66-73.

61. Kalra G. Talking about stigma towards mental health professionals with psychiatry trainees: a movie club approach. Asian J Psychiatr. 2012;5(3):266-8.

62. Mehrotra S, Tripathi R, Elias JK. Lay meanings of mental health in urban Indian college youth: insights for mental health promotion. J Community Appl Soc Psychol. 2013;23(4):286-99.

63. Roy A, Ikonen R, Keinonen T, Kumar K. Adolescents' perceptions of alcohol. Health Education (0965-4283). 2017;117(3):280-96.

64. Chavan BS, Patra S, Nebhinani N. Attitudes towards psychiatry in India. Ind J Psychiatry. 2016;58(5):S32.

65. Kermode M, Bowen K, Arole S, Pathare S, Jorm AF. Attitudes to people with mental disorders: a mental health literacy survey in a rural area of Maharashtra. India Soc Psychiatry Psychiatr Epidemiol. 2009;44(12):1087-96.

66. Bell JS, Johns R, Rose G, Chen TF. A comparative study of consumer participation in mental health pharmacy education. Ann Pharmacother. 2006:40:1759-65.

67. Gaiha SM, Sunil GA, Kumar R, Menon S. Enhancing mental health literacy in India to reduce stigma: the fountainhead to improve help-seeking behaviour. J Public Mental Health. 2014;13(3):146-58.

68. Math SB, Srinivasaraju R. Indian Psychiatric epidemiological studies: Learning from the past. Indian J Psychiatry. 2010;52(Suppl1):S95-S103.

69. Mann CE. Himelein, M. J. factors associated with stigmatization of persons with mental illness. Psychiatr Serv. 2004;55(2):185-7.

70. Jadhav S, Littlewood R, Ryder AG, Chakraborty A, Jain S, Barua M, et al. Ind J Psychiatry. 2007;49(3):189.

71. Evans-Lacko S, Brohan E, Mojtabai R, Thornicroft G. Association between public views of mental illness and self-stigma among individuals with mental illness in 14 European countries. Psychol Med. 2012;42(8):1741-52.

72. Bhui K, Bhugra D. Culture and mental health. London, United Kingdom: Edward Arnold; 2007.

73. Evans-Lacko S, Corker E, Williams P, Henderson C, Thornicroft G. Effect of the time to change anti-stigma campaign on trends in mental-illnessrelated public stigma among the English population in 2003-13: an analysis of survey data. Lancet Psychiatry. 2014;1(2):121-8.

74. McGorry PD, Tanti C, Stokes R, Hickie IB, Carnell K, Littlefield LK, et al. Headspace: Australia's National Youth Mental Health Foundation-where young minds come first. Med J Aust. 2007;187:S68-70.

75. Pescosolido BA, Perry BL, Krendl AC. Empowering the next generation to end stigma by starting the conversation: bring change to mind and the college toolbox project. J Am Acad Child Adolesc Psychiatry. 2020;59(4): 519-30.

76. Sontag-Padilla L, Dunbar MS, Ye F, Kase C, Fein R, Abelson S, Stein BD. Strengthening college students' mental health knowledge, awareness, and helping behaviors: the impact of active minds, a peer mental health organization. J Am Acad Child Adolesc Psychiatry. 2018;57(7):500-7.

77. Maulik PK, Devarapalli S, Kallakuri S, Tewari A, Chilappagari S, Koschorke M, et al. Evaluation of an anti-stigma campaign related to common mental disorders in rural India: a mixed methods approach. Psychol Med. 2017; 47(3):565-75.

78. Corrigan PW, Watson AC. Understanding the impact of stigma on people with mental illness. World Psychiatry. 2002;1(1):16-20.
79. Rayan A, Fawaz M. Cultural misconceptions and public stigma against mental illness among Lebanese university students. Perspect Psychiatr Care. 2018;54(2):258-65

80. Chung KF, Chan JH. Can a less pejorative Chinese translation for schizophrenia reduce stigma? A study of adolescents' attitudes toward people with schizophrenia. Psychiatry Clin Neurosci. 2004;58(5):507-15.

81. Sakellari E, Lehtonen K, Sourander A. Kalokerinou-Anagnostopoulou a, LeinoKilpi H. Greek adolescents' views of people with mental illness through drawings: mental health education's impact. Nurs Health Sci. 2014;16(3):358-64.

82. Gautam S, Jain N. Indian culture and psychiatry. Indian journal of psychiatry [Internet]. 2010; 52:[S309-S13 pp.]

83. Kato TA, Balhara YPS, Chawla JM, Tateno M, Kanba S. Undergraduate medical students' attitudes towards psychiatry: an international cross-sectional survey between India and Japan. Int Rev Psychiatry. 2013;25(4):378-84.

84. Koschorke M, Padmavati R, Kumar S, Cohen A, Weiss HA, Chatterjee S, et al. Experiences of stigma and discrimination of people with schizophrenia in India. Soc Sci Med. 2014;123:149-59.

85. $\mathrm{Ng} \mathrm{CH}$. The stigma of mental illness in Asian cultures. Aust N Z J Psychiatry. 1997;31(3):382-90.

86. Weiss MG, Jadhav S, Raguram R, Vounatsou P, Littlewood R. Psychiatric stigma across cultures: local validation in Bangalore and London. Anthropol Med. 2001;8(1):71-87.

87. Hofstede $\mathrm{G}$, Bond MH. The Confucius connection: from cultural roots to economic growth. Organ Dyn. 1988;16(4):5-21.

88. Papadopoulos C, Foster J, Caldwell K. 'Individualism-collectivism'as an explanatory device for mental illness stigma. Community Ment Health J. 2013;49(3):270-80.

89. Lauber C, Nordt C, Falcato L, Rössler W. Factors influencing social distance toward people with mental illness. Community Ment Health J. 2004;40(3): 265-74.

90. Gaebel W, Baumann A, Witte AM, Zaeske H. Public attitudes towards people with mental illness in six German cities. Eur Arch Psychiatry Clin Neurosci. 2002;252(6):278-87.

91. Adewuya AO, Makanjuola RO. Social distance towards people with mental illness amongst Nigerian university students. Soc Psychiatry Psychiatr Epidemiol. 2005;40(11):865-8.

92. Krendl AC. Pescosolido, B. a. countries and cultural differences in the stigma of mental illness: the east-west divide. J Cross-Cult Psychol. 2020;51(2):149-67.

93. Ahmedani BK. Mental health stigma: society, individuals, and the profession. J Soc Work Values Ethics. 2011;8(2):4 -1-4-16.

94. Colucci E, \& Lester, D. A cross-cultural study of attitudes toward suicide among young people in India, Italy and Australia. International Journal of Social Psychiatry [Internet]. 2020.

95. Dagur R, Jahagirdar A, Gautam A. A study to assess the effectiveness of planned teaching Programme on knowledge regarding preventive measures of suicidal behaviour among junior college students. Int J Nurs Educ. 2018;10(4):101-3.

96. Jasdeep K, Kiranjit K. A descriptive study to assess the knowledge regarding substance abuse among adolescent students of selected schools in Amritsar, Punjab with a view to develop information booklet. Asian J Nurs Educ Res. 2015;5(4):463-6.

97. Hemanthkumar B, Keertish N, Sathyanarayana M. Is there any difference between attitude of interns toward psychiatric illness and other chronic medical conditions? A comparative study. Indian J Psychiatry. 2018;60(2):195-8.

98. Dogra N, Vostanis P, Abuateya H, Jewson N. Understanding of mental health and mental illness by Gujarati young people and their parents. Divers Health Soc Care. 2005;2(2):91-7.

99. Doraiswamy P, Nattala P, Murthy P. How can today's substance-using youth be helped to quit? Perspectives of college students from Bangalore. India Int J Soc Psychiatry. 2020;66(5):469-75.

100. Dhandapani VR, Chandrasekaran S, Singh S, Sood M, Chadda RK, Shah J, et al, Community stakeholders' perspectives on youth mental health in India: problems, challenges and recommendations. Early Interv Psychiatry. 2020.

101. Chandra PS, Lakshmi S, Nanjundaswamy MH, Shiva L. The impact of urbanization on mental health in India. Curr Opin Psychiatry. 2018;31(3):276-81.

102. Shaikh BM, Doke PP, Gothankar JS. Depression, anxiety, stress, and stressors among rural adolescents studying in Pune and a rural block of Nanded district of Maharashtra. India Ind J Public Health. 2018;62(4):311-4.

103. Verma A, Rao AP, Andrews T, Binu VS. Assessment of level of stress and depression among adolescents in Udupi taluk. Karnataka Ind J Community Health. 2019;31(1):132-6. 
104. Mackinnon N, Bhatia U, Nadkarni A. The onset and progression of alcohol use disorders: a qualitative study from Goa, India. J Ethn Subst Abus. 2019; 18(1):89-102.

105. Rani A, Jaisoorya TS, Menon PG, Nair BS, Jeevan CR, Radhakrishnan KS, et al. Harm from other people's drinking among college students in India. Drug Alcohol Rev. 2019;38(7):774-80.

106. Ganesan S, Ravishankar SL, Ramalingam S. Are body image issues affecting our adolescents? A cross-sectional study among college going adolescent girls. Indian J Community Med. 2018;43:S42-S6.

107. Pathak P, Kukreti V, Bisht AT. Parental perceptions, depression and BMI: a road to understand the occurrence of vulnerability to anorexia in adolescent girls. Online J Health Allied Sci. 2019;18(3):1-3.

108. Anand T, Kishore J, Grover S, Bhave S, Yadav S. Beliefs supporting violence, attitudes and aggressive behavior among school adolescents in rural Delhi. Community Ment Health J. 2019:55(4):693-701.

109. Borse K, Prasad K. Assessment of parental pressure and peer factors affecting the performance of undergraduate nursing students studying in selected nursing colleges of Maharashtra. Nurs J India. 2019;110(1):3-7.

110. Parikh R, Sapru M, Krishna M, Cuijpers P, Patel V, Michelson D. "It is like a mind attack": stress and coping among urban school-going adolescents in India. BMC Psychol. 2019;7(1):31.

111. Long KNG, Gren LH, Long PM, Jaggi R, Banik S, Mihalopoulos NL. A picture of Indian adolescent mental health: an analysis from three urban secondary schools. Int J Adolesc Med Health. 2017;31(4):20170035.

\section{Publisher's Note}

Springer Nature remains neutral with regard to jurisdictional claims in published maps and institutional affiliations.

Ready to submit your research? Choose BMC and benefit from:

- fast, convenient online submission

- thorough peer review by experienced researchers in your field

- rapid publication on acceptance

- support for research data, including large and complex data types

- gold Open Access which fosters wider collaboration and increased citations

- maximum visibility for your research: over $100 \mathrm{M}$ website views per year

At $\mathrm{BMC}$, research is always in progress.

Learn more biomedcentral.com/submissions 